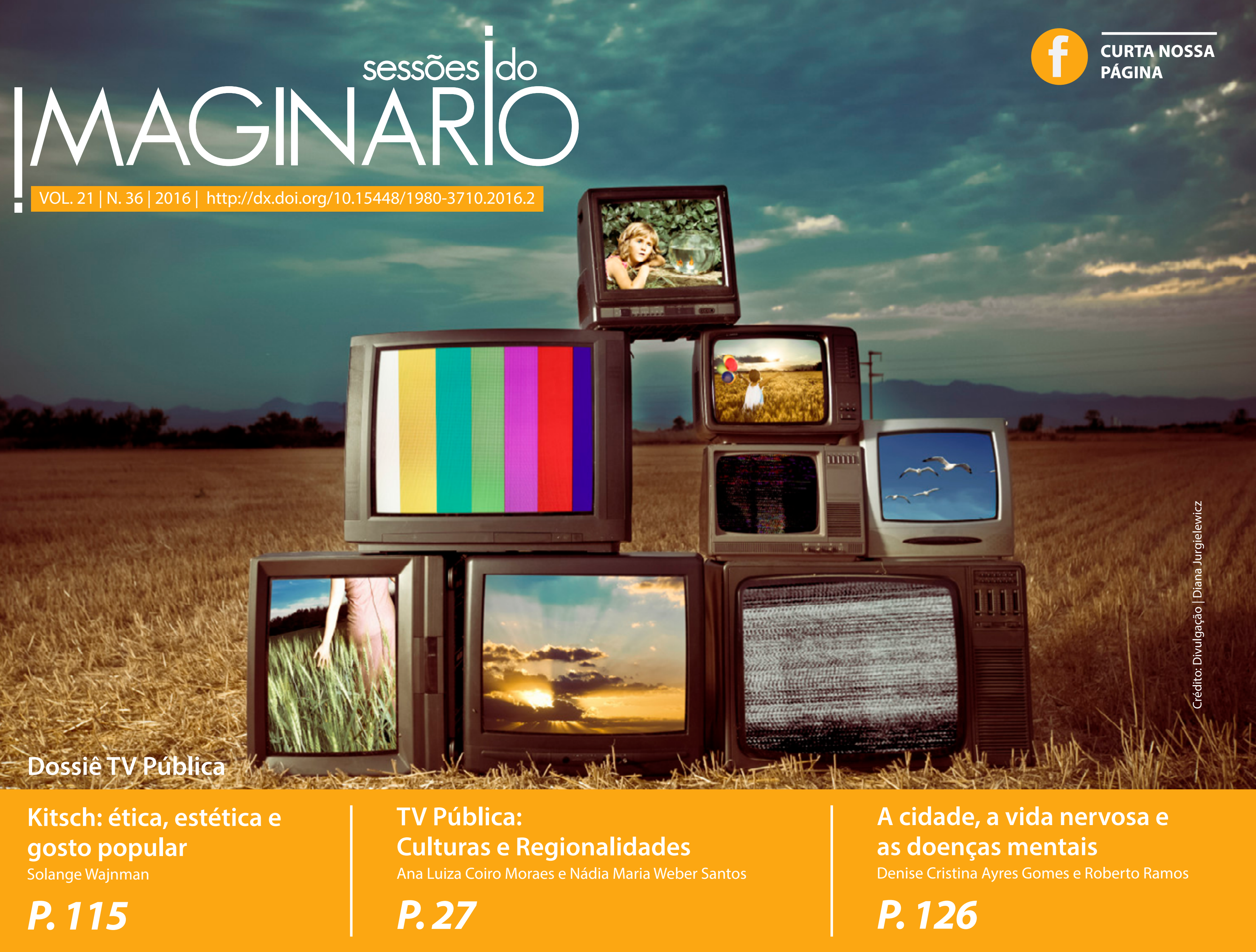




\section{A cidade e a vida nervosa: O imaginário sobre as doenças mentais na Folha de S. Paulo}

The city and the nerve life: the imaginary about mental illness in the Folha de S. Paulo

\section{Denise Cristina Ayres Gomes [}

Roberto José Ramos ${ }^{2}[$

\section{Resumo}

O artigo enfoca o imaginário urbano sobre as doenças mentais em nove matérias do jornal Folha de S. Paulo (FSP). Utilizamos a Sociologia Compreensiva de Michel Maffesoli (2010) e identificamos que o imaginário pós-moderno revela a saturação da identidade, o trágico (Maffesoli, 2003) e o corpo paroxístico. O jornalismo, como "tecnologia do imaginário" (Silva, 2012), tende a agregar as pessoas dispersas nas grandes cidades, onde o ritmo acelerado desencadeia a "saturação dos nervos" e requer novas formas de interação.

\section{Palavras-chave}

Imaginário; jornalismo; doenças mentais.

\section{Abstract}

The article focuses on the urban imaginary about mental illness in nine news from Folha de S. Paulo (FSP). We used the Michel Maffesoli (2010) Comprehensive Sociology and identified that postmodernity reveals the saturation of identity, the tragic (Maffesoli, 2003) and body paroxysmal. Journalism, as "imaginary technology" (Silva, 2012), tends to add people scattered in major cities, where the fast pace triggers the "saturation of nerves" and requires new forms of interaction.

\section{Keywords}

Imaginary; journalism; mental illness. 


\section{Introdução}

Em 1903, George Simmel (2005) proferiu a palestra As grandes cidades e a vida do espírito, também traduzida como A metrópole e a vida mental em que constata o esgotamento mental dos indivíduos devido ao excesso de estímulos do cotidiano urbano. Como forma de se adaptar às exigências das cidades grandes, as pessoas se tornariam indiferentes ou blasées.

Um século depois, observamos que a "saturação dos nervos", evidenciada por Simmel (2005), provoca a explosão do número de pessoas com transtornos psíquicos no meio urbano. Há cerca de 450 milhões de doentes no mundo, sendo 23 milhões no Brasil (OMS, 2001). A região metropolitana de São Paulo é considerada como a de maior incidência de doenças mentais entre os países pesquisados (IPqUSP; OMS, 2012).

Manifestações de comportamentos considerados estranhos ou que provocam sofrimento sempre existiram. Na Grécia Antiga, o louco é possuído por espírito divino. Na Idade Média predomina a concepção demonista das perturbações. $O$ imaginário moderno instaura a concepção mecanicista do universo e o conceito de doença mental. $\mathrm{Na}$ pós-modernidade, o sofrimento passa cada vez mais a ser intensificado, tecnicizado e midiatizado.

O dispositivo jornalístico integra o ambiente tecnológico pós-moderno em que a mídia se torna matriz de sociabilidade. A Folha de S. Paulo (FSP) traduz as doenças mentais em formas que circulam na sociedade, produzem sentidos e criam ambiência. O imaginário permeia a sociedade, vincula as pessoas, é atmosfera, espécie de aura circundante que promove coesão social (Maffesoli, 2001). O jornalismo afeta o imaginário porque utiliza a técnica própria da profissão para modificar, desvelar e atribuir sentido ao mundo, por isso, constitui-se em uma tecnologia do imaginário (Silva, 2012).

Selecionamos nove matérias dos anos 2001 e 2011 e utilizamos a noção de imaginário (Maffesoli, 2001) e os pressupostos da sociologia compreensiva de Michel Maffesoli (2010). Oobjetivo deste estudoécompreender o imaginário urbano sobre as doenças mentais a partir do discurso jornalístico da Folha de S. Paulo. Identificamos o imaginário através de metáforas e destacamos a saturação da identidade, o trágico (2003) e o corpo paroxístico, formas que integram a pós-modernidade.

\section{O imaginário e as doenças mentais}

O imaginário tem algo de imponderável, irracional e abarca as esferas lúdica, onírica, afetiva e simbólica (Maffesoli, 2001). A ambiência partilhada mobiliza as pessoas em torno de valores e sentimentos comuns. $O$ imaginário é real porque fomenta processos interativos na esfera prática. "Todos os documentos - iconográficos ou textuais - comportam uma parte do imaginário, assim como todos os discursos. Toda expressão humana, pois, carrega consigo as marcas, mesmo ínfimas, da imaginação criadora" (Legros, 2014, p.108).

A pós-modernidade é marcada pelo imaginário trágico ou dionisíaco (Maffesoli, 2003). A metáfora proposta compara a contemporaneidade a Dionísio, o deus do excesso, conjuntivo e carnal, trágico e presenteísta. Tal personagem ambivalente da Antiguidade grega traduz a pós-modernidade, ambiente que evoca o estar-junto, a vivacidade, o paradoxo, o relativismo, a premência da forma corporal e a transitoriedade da existência.

Utilizamos a metáfora como recurso da sociologia compreensiva e distinguimos três formas que revelam o imaginário pós-moderno: a saturação da iden- tidade, o trágico e o corpo paroxístico. Tais formas se manifestam, sobretudo nas grandes cidades onde 0 ritmo acelerado, a competitividade no trabalho, as relações permeadas pelo dinheiro e a instabilidade nas várias esferas sociais provocam o esgotamento mental e o consequente aumento dos transtornos psíquicos.

\section{A saturação da identidade}

O conceito moderno de indivíduo, considerado racional e unificado se satura e assume novas formas de contornos indefinidos que denominamos identificações. Maffesoli (2006) propõe o termo pessoa (persona ou máscara) para descrever o caráter efêmero do indivíduo, atrelado às circunstâncias e evoluindo para a representação de papéis que só fazem sentido em relação ao outro.

Embora o sofrimento seja sentido no corpo individual, a doença participa de uma atmosfera de partilha. De acordo com a perspectiva orgânica adotada por Maffesoli (2006), a pessoa se inscreve em um todo coletivo, sinergia que fortalece o domínio da vida.

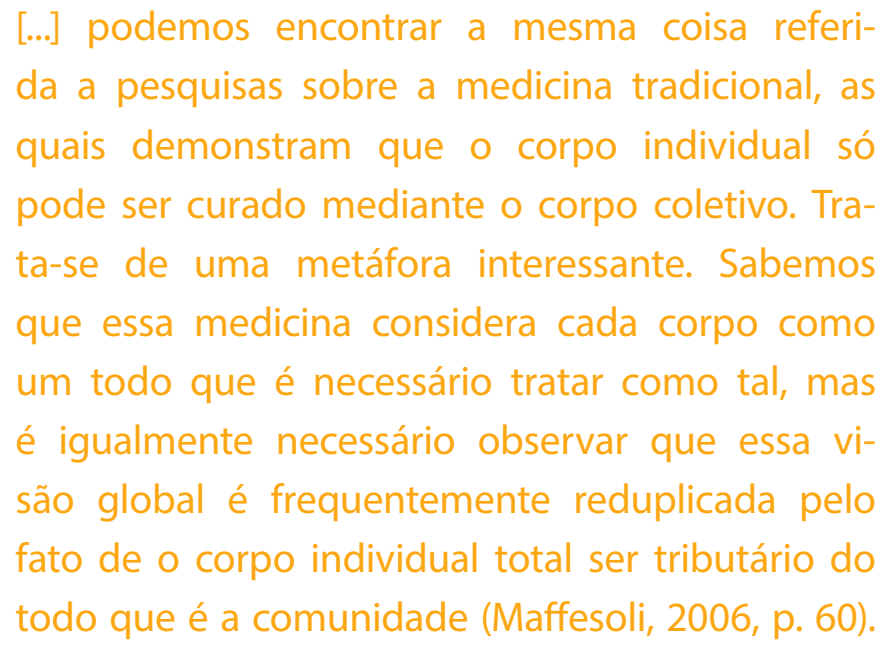


Como aponta Simmel (2005), as relações nas cidades grandes tendem a ser mais impessoais, objetivas e intelectualizadas. Na pós-modernidade essas características se tornam insuficientes para compreender a realidade. A vida social não pode ser mais concebida a partir de leis econômicas racionais e restritivas; é preciso considerar os aspectos lógico e não lógico que modelam os fenômenos. A comunicação potencializada pelo desenvolvimento tecnológico estrutura o cotidiano. Estudar as doenças mentais implica levar em conta o sentimento, o orgânico e a imaginação.

Ojornalismo potencializa vínculos emocionais e novas formas de agregação. As pessoas se unem por afinidades e, em nosso caso, procuram aliviar o sofrimento, são solidárias, buscam grupos de apoio e falam de seus males no jornal. Enquanto a modernidade calou os doentes mentais nos manicômios, na pós-modernidade, o sofrimento é intensificado e compartilhado na mídia.

\section{O trágico}

O vitalismo, que nos impele à comunhão, é uma espécie de resposta ao sentido trágico da pós-modernidade, expresso na figura de Dionísio. Esse deus grego simboliza a desmedida, o paradoxo, o relativismo, a emoção, a falta de limites, a união com a natureza e a ordem confusional. A forma trágica aceita o destino como inelutável, a impermanência de todas as coisas e a fragilidade do conhecimento. Daí a intensidade no viver, excessos e paroxismos que moldam as relações e os comportamentos cotidianos e se manifestam no sofrimento mental.

O trágico é a aceitação incondicional do caráter sofredor e absurdo próprio da existência humana. Viver é estar imerso na inconstância, à mercê dos acontecimen- tos incontroláveis. A vida é considerada um fato, uma necessidade, então, resta vivê-la de modo intenso e sem adiamento. O homem se volta para o corpo, experimenta a alegria do viver, valoriza o prazer, a força e a saúde.

A ciência não deve ter a pretensão de abarcar todos os fenômenos à procura de estabelecer leis previsíveis e universais. Onde reina a ordem absoluta, não pode haver criação, não há espaço para possibilidades, apenas determinação. O trágico revela a condição humana; falível e imperfeita e abarca o paradoxo. O homem é marcado pela ambiguidade e tenta se equilibrar entre o interior mental e a realidade objetiva, constituindo-se sapiens e demens (razão e loucura)

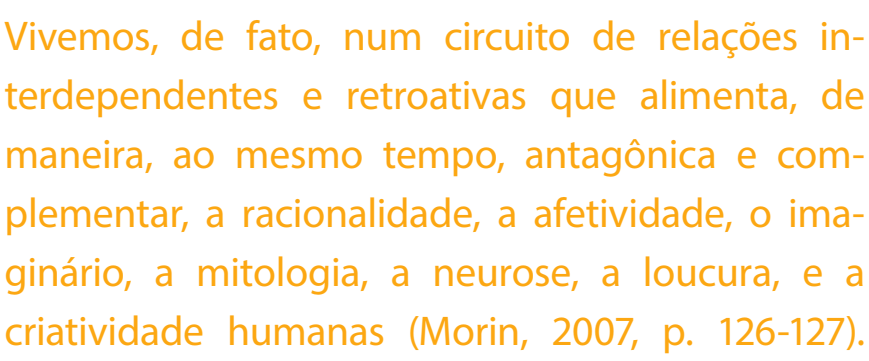
terdependentes e retroativas que alimenta, de maneira, ao mesmo tempo, antagônica e complementar, a racionalidade, a afetividade, o imaginário, a mitologia, a neurose, a loucura, e a criatividade humanas (Morin, 2007, p. 126-127).

O turbilhão de interpelações que nos demandam todos os dias criou um ambiente instável e emocional que reifica a ação instantânea. Qualquer pessoa é passível de manifestar um transtorno porque é constitutivamente paradoxal. Nem mesmo aquela considerada símbolo de sucesso, fama ou fortuna, escapa do sofrimento.

A forma da espiral expressa o imaginário trágico e contempla a organicidade do mundo. Enquanto a modernidade se manifesta nas linhas retas e verticais, a pós-modernidade se abre às emoções e contempla as esferas natural e social. A verticalidade é símbolo da dominação da natureza, da racionalidade instrumental e utilitarista que busca explicar a realidade. "É contra esta que se opõe a espiralidade que segue os meandros das eflorescências naturais ou o labirinto do vivido" (Maffesoli, 2010a, p. 100-101). A espiral, portanto, abarca as emoções.

O trágico provoca o retorno cíclico de todas as coisas e imobiliza o tempo, fazendo com que o instante seja vivido intensamente. Se a modernidade criou o tempo útil, produtivo, linear e progressivo, a pós-modernidade se depara com o presente, o constante pulular dos acontecimentos que nos conecta a tudo que é momentâneo. $A$ ambiência que enfatiza o viver aqui e agora é manifesta na forma do corpo paroxístico.

\section{O corpo paroxístico}

Diante da fatalidade, existe a vontade de viver o presente que se exprime pela intensidade da sensação e da ação. A descrença no futuro, a perda da força normativa da tradição, a falta de projeto, a impossibilidade do adiamento, a gratificação momentânea e a incerteza do porvir produzem as manifestações do excesso e a acentuação do tempo presente. "Viver a morte de todo o dia, talvez seja isso o que exprime melhor o que nós entendemos por intensidade e monotonia do presente" (Maffesoli, 1987, p. 52).

A pós-modernidade enaltece o corpo, o fenômeno que dá forma à existência, a aparência que agrega, a materialidade que provoca sensações e implementa o imaginário. A exacerbação do presente ou presenteísmo (Maffesoli, 2003) acarreta a pregnância da forma, o corpo inscrito em uma localidade que o legitima. A forma corpórea participa de uma espécie de encenação, espetáculo que produz socialidade, a emoção de estar junto.

$O$ pensamento e a linguagem deixaram de ser preponderantes na descrição das patologias con- 
temporâneas. O paciente não precisa mais recorrer a sua história de vida, articular episódios traumáticos para ressignificá-los, como requeria a psicanálise. As perturbações estão expostas no mal-estar corpóreo e na maneira como o indivíduo age.

O corpo é instrumento performático, forma que revela sentimentose emoções, portanto, está voltado para a alteridade. O que denominamos "corpo paroxístico" é expresso na intensificação dos sintomas da doença mental. O jornalismo se detém sobre os aspectos da patologia que mais chamam a atenção para construir a notícia.

[...] O encurtamento ou a condensação das formas de linguagem que a pós-modernidade reserva ao sofrimento parece ter redundado também em redução da extensão e em mutação na qualidade da queixa, sob a qual opera o diagnóstico. Temos agora novas patologias baseadas no déficit narrativo, na incapacidade de contar a história de um sofrimento, na redução do mal-estar à dor sensorial (Dunker, 2015, p. 33)

A pós-modernidade marca a explosão do número de pessoas afetadas por doença mental. Existem cerca de 450 milhões de indivíduos sofrendo de algum transtorno no mundo, sendo 23 milhões somente no Brasil (OMS, 2001). A região metropolitana de São Paulo é abordada em pesquisas internacionais por ter a maior incidência de transtornos mentais entre 24 países pesquisados. Os números são expressivos: 19,9\% da população possui transtornos de ansiedade e 11\% têm transtornos depressivos (IPqUSP; OMS, 2012).

A regulação do mal-estar corpóreo ocorre pela ação dos psicofármacos que prometem alívio imedia- to. O uso desses medicamentos tem se generalizado de forma indiscriminada para enfrentar as banalidades do cotidiano. A psicofarmacologia remete ao triunfo do discurso científico que afirma ser capaz de regular o sofrimento e explicar de forma racional, o lado afetivo do ser humano. O sofredor é um sujeito que não se adapta à sociedade e precisa ser controlado.

\section{O jornalismo como produtor de imaginário}

O jornalismo promove interação social, modela a vida cotidiana e agrega a realidade fragmentada e diversa da experiência. $A$ atividade jornalística é uma forma de conhecimento que parte da realidade factual e incorpora seus aspectos mais relevantes ou paroxísticos para transformá-los em notícia. A atividade dramatiza os fenômenos, teatraliza o cotidiano com o intuito de atrair a atenção, produzir sensações, informar, orientar o público e vender notícia.

A Folha de S. Paulo (FSP) dá forma, reconstrói e amplifica o discurso da medicina, característica de um ambiente estruturado pela mídia. Nesse caos evenemencial, o jornalismo tem importância preponderante como ordenador das concepções dos sujeitos acerca do mundo. As notícias dotam a realidade de sentido. "[...] Por meio dele [o noticiário], também esperamos ter revelações, aprender o que é certo e errado, conferir sentido ao sofrimento e entender como funciona a lógica da vida" (Botton, 2015, p. 11). O discurso jornalístico traduz o sofrimento em formas simbólicas que são partilhadas na sociedade e se tornam vetores de interação social, isto é, de comunicação.

A técnica jornalística traz à tona o que estava escondido e, ao revelar, modifica a realidade. "[...] O jornalismo produz versões. Produzir, no sentido heideggeriano, sig- nifica fazer passar do estado escondido ao não escondido. Revelar. Essa seria a essência do jornalismo" (Silva, 2012, p. 104). O jornalismo é uma "tecnologia do imaginário" porque tende a direcionar os sentidos no social.

Ao mesmo tempo em que desvela o mundo, a técnica jornalística afeta os fatos cobertos e o próprio sujeito. O apelo jornalístico não é apenas racional e opera na esfera da emoção e do irracional visando produzir sensações. A espetacularização é intrínseca à atividade que faz uso da dramatização, do pitoresco, da personalização e outras estratégias para seduzir (Silva, 2012). A técnica jornalística transforma o sofrimento do estado biológico e subjetivo para um fenômeno de dimensão social e simbólica que normatiza condutas, institui práticas, desperta sentimentos, mobiliza pessoas, produz significados, implica valores e constitui o imaginário.

\section{A sociologia compreensiva e o imaginário}

Utilizamos a sociologia compreensiva de Maffesoli (2010), abordagem que descreve e compreende os fenômenos como eles são. O método compreensivo ultrapassa a observação pura e considera as dimensões físicas (objetivas) e psíquicas (subjetivas) para problematizar o sentido que as justifica.

A sociologia compreensiva "descreve o vivido naquilo que é/está" (Maffesoli, 2010, p. 30). Ao rejeitar o dualismo sujeito/objeto, admitimos o pesquisador implicado no objeto de maneira empática. O conhecimento somente pode ser algo comum, constituído por meio da intersubjetividade e o contato com a realidade dada.

Consideramos dois pressupostos da sociologia compreensiva de Maffesoli (2010); o primeiro é a "crítica ao dualismo esquemático". O objeto de pesquisa não é considerado uma realidade separada do pes- 
quisador, da qual se podem deduzir leis e princípios. A sociologia compreensiva se funde ao objeto e adota o ponto de vista metanoico. $O$ procedimento não possui interesses teleológicos, objetivos, utilitários e racionais e considera a relatividade de todas as coisas.

A pós-modernidade implica a saturação dos esquemas totalizantes, a emergência do politeísmo de valores e o predomínio das emoções. O outro pressuposto da sociologia compreensiva é "a sensibilidade relativista" que considera o dado social como fenômeno complexo e constitutivamente paradoxal. "Há uma lógica contraditorial que se opõe ao princípio ou à lógica da identidade [...]" (Maffesoli, 2010, p. 62). Adotamos o procedimento metodológico em perspectiva, relativista e contingente.

Selecionamos a Folha de S. Paulo (FSP) por ser o jornal de maior circulação paga em âmbito nacional com média de 351.745 exemplares (ANJ, 2014). Além de ser veículo de referência nacional, a escolha considerou o fato de a região metropolitana de São Paulo possuir o maior índice de doença mental entre os países pesquisados (OMS, 2012).

Os textos compõem o arquivo digital da Folha de $S$. Paulo e foram escolhidos por meio dos recursos disponíveis no site "busca detalhada" e "frase exata", utilizando as palavras-chave "doença mental". As nove matérias se referem aos anos de 2001 e 2011, quando se inicia a pós-modernidade, conforme consideramos, e ano da aprovação da lei da reforma psiquiátrica no Brasil e a década posterior. A saturação da identidade, o trágico e o corpo paroxístico são formas que expressam o imaginário pós-moderno e estão presentes nos textos estudados.

\section{A saturação da identidade na} Folha de S. Paulo

Compreendemos que o imaginário pós-moderno é marcado pela saturação da identidade. O jornalismo, como ordenador da vida social na pós-modernidade, dissemina informações que circulam na sociedade e produzem ambiência, isto é, imaginário. A doença mental se torna um fenômeno partilhado no coletivo.

A abertura para compartilhar o sofrimento com o outro, falar do mal, procurar ajuda, tornar-se personagem de uma narrativa jornalística e buscar grupos de apoio são marcas da abertura para a alteridade. A doença provoca empatia e solidariedade. Embora caiba à medicina a tarefa de distinguir as patologias, as pessoas têm o impulso vital de se reconhecerem no sofrimento e procurar ser solidárias para amenizar a dor

A reportagem intitulada "Afastamentos por doenças mentais disparam no país" afirma que a divulgação de informações sobre transtornos psíquicos motiva as pessoas a buscarem tratamento e acarreta o afastamento do trabalho. "Especialistas ressaltam que os trabalhadores têm acesso atualmente a mais informações sobre os transtornos mentais e suas causas. 'Isso também ajuda a explicar o aumento nas concessões"' (Fraga; Borlina Filho, 2011).

Observamos a realidade social matizada pela esfera simbólica que institui valores e práticas. "Há ondas de doenças de trabalho. A onda atual é a da saúde mental" (Fraga; Borlina Filho, 2011). A "onda" somente é possível porque há comunicação, isto é, as pessoas partilham do mesmo imaginário sobre o sofrimento. Como consequência, houve o aumento da procura para concessões de benefícios de auxílio-doença. Outro trecho evidencia a importância da comunicação: "[...] o maior acesso à infor- mação e a globalização contribuem para a maior ocorrência de doenças mentais" (Fraga; Borlina Filho, 2011).

A matéria da Folha deS. Paulo, intitulada "O teste dos temperamentos" (Versolato, 2011), enfoca o site criado por psiquiatras da Pontifícia Universidade Católica do Rio Grande do Sul (PUCRS) que traça o perfil psicológico e psiquiátrico dos internautas. O texto jornalístico dá detalhes sobre o teste e explica os doze tipos de temperamentos considerados. Os psiquiatras citados concordam com a utilidade do site. "Para Del Porto [psiquiatra], o serviço não tem a pretensão de servir como um diagnóstico, mas pode motivar a pessoa a procurar tratamento especializado, o que é positivo" (Versolato, 2011).

Mais uma evidência de que o jornalismo promove a abertura para o outro se encontra neste trecho: "O primeiro remédio, na verdade, é a informação, explica" (Maldjian, 2011). A fonte se refere a Roberto Carlos e Luciana Vendramini, que revelaram a diversos veículos e na própria Folha de S. Paulo, serem portadores de transtorno obsessivo compulsivo (TOC). Os exemplos dos famosos incentivaram pessoas a buscarem tratamento. "O Roberto e a Luciana não têm ideia do quanto eles encorajam, até hoje, as pessoas" (Maldjian, 2011). O trecho mostra a importância da mídia na disseminação de sentidos que intervêm no social. A narrativa jornalística produz imaginário que permeia eatua sobre o cotidiano.

A matéria mostra que a doença de Roberto Carlos, contada em uma revista, serviu de inspiração para que determinada mãe identificasse o transtorno da filha. "[...] a mãe chegou em casa afobada, sacudindo uma revista. 'Olha, Andressa, você tem a mesma coisa que o Roberto Carlos'"' (Maldjian, 2011). O discurso jornalístico promove a exterioridade, as trocas intersubjetivas, o compartilhamento de experiências e afetos que dotam o cotidiano de sentido. 
A coluna intitulada "SOS TOC" compõe a matéria e enumera os "grupos de apoio e orientação de tratamento" (Maldjian, 2011). O texto incita as pessoas a se reconhecerem como pertencentes a grupos patológicos e buscar ajuda. Como afirma Maffesoli (2006), a pós-modernidade é um ambiente emocional, em que as pessoas se juntam por empatia, são solidárias e, no caso deste estudo, partilham o sofrimento. Ainda que haja o poder institucional da medicina agindo sobre as pessoas, e o jornalismo prescrevendo o dever-ser, existe a identificação com o outro, a iniciativa de exteriorizar o sofrimento nas páginas do jornal e aliviar a dor alheia.

Compreendemos que o jornalismo produz socialidades. Alguém que se percebe doente, ao ler um texto jornalístico, referencia seu sofrimento ou depessoas próximas e tende a procurar ajuda médica, buscar amparo entre familiares e grupos de apoio. "Com o teste, pelo menos a pessoa pode perceber se tem algum problema" (Versolato, 2011). O sofrimento somente adquire sentido na intersubjetividade. Quem sofre partilha a atmosfera permeada de sentidos disseminados pelo jornalismo.

A reportagem "Motivação evita recaída no alcoolismo" (Stringueto, 2001) reúne vários dados e declarações de fontes para comprovar que o doente deve se submeter à terapia para ter maior probabilidade de se recuperar. "[...] a melhor estratégia de combate ao alcoolismo é mesmo o AA (Alcoólicos Anônimos). Um programa baseado em reuniões (diárias ou semanais dependendo da disponibilidade do paciente) de vários alcoólicos com a finalidade de trocar experiências" (Stringueto, 2001).

A reportagem traz ainda a coluna "Onde procurar ajuda, tratamentos e informações", listando vários locais de apoio aos alcóolatras com endereço e telefone. A Folha de S. Paulo pratica o jornalismo de serviço e tende a promover que as pessoas busquem ajuda para o alcoolismo. Compreendemos que o discurso jornalístico produz socialidades quando dissemina sentidos e induz as pessoas a buscarem apoio, tornando-se indispensável e útil para o cotidiano. Cada vez mais, a doença mental é externalizada, midiatizada e compartilhada.

\section{O trágico na Folha de S. Paulo}

O sentido trágico do imaginário permeia a questão das doenças mentais. A medicina admite o controle dos sintomas, já que não existe cura para muitas patologias. Trata-se de aceitar o diagnóstico e conviver com ele, procurando regular o mal-estar evidenciado no corpo e não apenas buscar a causa ou a cura da patologia. Como no exemplo: "'Quando ele me disse que o TOC não tinha cura, eu comecei a chorar', lembra"' (Maldjian, 2011).

A matéria intitulada "Problema mental pode ser camuflado" (Valdejão, 2001) aponta que os fenômenos são complexos, nebulosos e paradoxais. A doença mental não pode ser definida claramente. "Os psiquiatras são unânimes na avaliação de que é difícil distinguir quando alguém ultrapassa a tênue linha que separa a normalidade da anormalidade". Loucura e razão são complementares e constitutivas do ser humano, como afirma Morin (2007)

O trecho da matéria intitulada "Brasileiros criam diagnóstico para pânico" (Massarani, 2001) mostra a debilidade do conhecimento científico. "Como outras doenças mentais, ainda não se conhecem, de maneira clara, as causas do transtorno do pânico. Acredita-se que haja um fator hereditário". A crença traduz a relativização da ciência tomada como narrativa à procura de esclarecer os fenômenos.
O texto intitulado "Estudo relaciona esquizofrenia com vírus" (FSP, 11 abr. 2001) aponta os limites da ciência. "Mudanças no funcionamento do cérebro também foram identificadas, mas suas causas permanecem desconhecidas". Em outro trecho, a matéria afirma: "No entanto, os cientistas não sabem dizer se essas sequências virais são resultado da infeção por retrovírus".

O imaginário trágico aponta a instabilidade em todas as esferas que se traduz nas doenças mentais. A bipolaridade é o transtorno característico do paradoxo pós-moderno. A doença alterna episódios de extrema euforia e depressão, sendo a ciclotimia um dos subtipos. "Em alguns casos de euforia dentro do transtorno bipolar (alternância de episódios de depressão e euforia), por exemplo, o quadro é agudo" (Valdejão, 2001); "[...] Se o resultado disser que sou muito instável, será que não tenho ciclotimia, um transtorno de humor?" (Versolato, 2011).

Observamos o imaginário trágico manifesto no turbilhão de interpelações a que estamos expostos no dia a dia. Vivemos à mercê dos acontecimentos, obrigados a dar respostas constantes para as demandas. A pós-modernidade é instável, remete ao instante e às circunstâncias. As grandes cidades é o ambiente onde se observa a exacerbação e o esgotamento das emoções devido ao excesso.

A reportagem "Pressões e problemas urbanos colaboram para afastamento" aborda como o "cotidiano das grandes cidades faz com que as pessoas vivam estressadas" (Cézari, 2011). O texto afirma: “Em tempos de 'salve-se quem puder', as pessoas são pressionadas a produzir mais, a vender mais, a melhorar a qualidade dos produtos. Quem não entra nessa espiral fica para trás". A reportagem cita fatores que 
colaboram para o aumento das doenças mentais entre os trabalhadores como a cobrança das empresas, a "competitividade, os problemas familiares e pessoais, os sociais, o trânsito caótico das grandes cidades e a violência urbana" (Cézari, 2011). Os mais velhos sofrem ainda com a adaptação às novas tecnologias.

A vida urbana no Brasil revela as contradições sociais do país. Nas cidades, as diferenças entre ricos e pobres são mais acentuadas e contribuem para o desenvolvimento dos transtornos. A reportagem intitulada "Doença mental afeta mais criança favelada" atesta as contradições. "Crianças faveladas têm quase o dobro de chances de desenvolver distúrbios mentais do que as de classe média e as da zona rural". "Embora seja conhecida como 'Suíça', Campos [do Jordão] é uma cidade em que convivem mansões de milhões de reais e morros apinhados de favelas" (Medeiros, 2001).

Como aponta Simmel (2005), a vida urbana intensifica os nervos e provoca a indiferença como recurso de adaptação. Compreendemos que as grandes cidades afetam as emoções de tal forma a provocar doenças, a exemplo dos altos índices de transtornos psíquicos na região metropolitana de São Paulo (OMS, 2012). "Pareceria, para retomar uma expressão de Georg Simmel, que se assiste, com a pós-modernidade, a uma 'intensificação da vida dos nervos'" (Maffesoli, 2010a, p. 36). Cabe lidar com o sofrimento, procurando minimizá-lo com remédios. Ninguém está imune às doenças mentais, sejam os personagens desconhecidos que ilustram as matérias, até as pessoas consideradas símbolos de sucesso. Afinal, como disse uma fonte: "Se o Rei tem TOC, qual é o problema de nossos filhos e alunos terem, poxa?" (Maldjian, 2011).
O corpo paroxístico na Folha de S. Paulo

O imaginário pós-moderno se manifesta na proeminência da forma corporal que remete à presença, ao instante. $O$ corpo sintetiza a urgência de viver aqui e agora, é presença, volta-se para a exterioridade, é instrumento performático e passível de ser modelado. O registro corporal é investido de cuidados e está ligado às emoções.

No lugar das antigas modalidades de sofrimentos centrados no conflito psíquico, nos quais se opunham os imperativos das pulsões e os das interdições morais, o mal-estar se evidencia agora como dor, inscrevendo-se nos registros do corpo, da ação e das intensidades (Birman, 2012, p. 65).

Verificamos as formas de sofrimento expressas no mal-estar corpóreo e na performatividade da ação exacerbada. Como nos exemplos que caracterizam o TOC, considerado um transtorno de ansiedade: "o cantor não saía de um lugar pela porta que entrou, não usava marrom e não dizia palavras negativas: parou até de cantar um dos seus sucessos, 'Quero Que Vá Tudo pro Inferno'". Outro trecho demarca o excesso: "Como se não bastasse a fissura pela higiene, ela também se apega à simetria" (Maldjian, 2011).

Observamos que a regulação do mal-estar corpóreo ocorre, principalmente, através do uso de medicamentos, intervenção pontual de natureza neurobioquímica que atenua os sintomas corporais. A terapia desempenha papel coadjuvante na pós-modernidade, ambiente em que as pessoas procuram alívio imediato para o sofrimento. Os trechos ilustram o uso de medicação: "De imediato, Andressa procu- rou um psiquiatra e começou a se tratar com remédios" (Maldjian, 2011). "Há um ano, Diogo, 12, também encara o tratamento recomendado - medicamentos como antidepressivos e terapia" (Maldjian, 2011).

Outro indício do corpo paroxístico é a manifestação dos transtornos mentais que irrompe e modifica o comportamento de forma brusca. "De uma hora para outra, cismou que tinha Aids. Depois entrou em desespero por pensar que havia abortado. A verdade ela e a família só descobriram seis anos depois: ela tem esquizofrenia" (Valdejão, 2001). Outro trecho demarca o excesso: "Deixaram-me sozinha para cuidar de quatro pacientes. Um deles 'parou', deu tudo errado. Daí surtei" (Fraga; Borlina Filho, 2011).

O transtorno obsessivo compulsivo é classificado como um transtorno de ansiedade acompanhado de obsessões e compulsões que consomem tempo excessivo e causam sofrimento. Os exemplos mostram comportamentos típicos de pessoas que partilham a mesma doença. As ações seguem uma lógica interna que somente faz sentido para quem participa do ritual, tentativa de manutenção da vida. "'A obsessão é aquele pensamento, mesmo sem sentido, que a pessoa não consegue tirar da cabeça. E a compulsão é o ritual feito para afastá-lo', explica Ana Hounie, psiquiatra do Hospital das Clínicas de São Paulo" (Maldjian, 2011).

O indivíduo é invadido por pensamentos, imagens repetitivas que o obrigam a criar rituais na tentativa de neutralizá-los. "Naquele tempo, criou outro comportamento repetitivo, engolir saliva olhando para cima, 'para não absorver algo do inferno'”. " "...] Se eu não lavar as mãos, não vou conseguir conversar com você"; “[...] Se eu tocar no chão, no rejunte dos pisos, por 
exemplo, acho que vou me contaminar"; "[...] No início, ela só conseguia dormir depois de ver três táxis amarelos. No auge, ficou dez horas no chuveiro, esperando um pensamento bom vir à mente" (Maldjian, 2011).

Os rituais típicos das pessoas portadoras de transtornoobsessivo-compulsivoilustramodeter-senoinstante, o eterno presente que se impõe. Como afirma Andressa, a personagem da matéria, a aflição é atenuada quando lava as mãos. $O$ ritual expressa a imobilização do tempo.

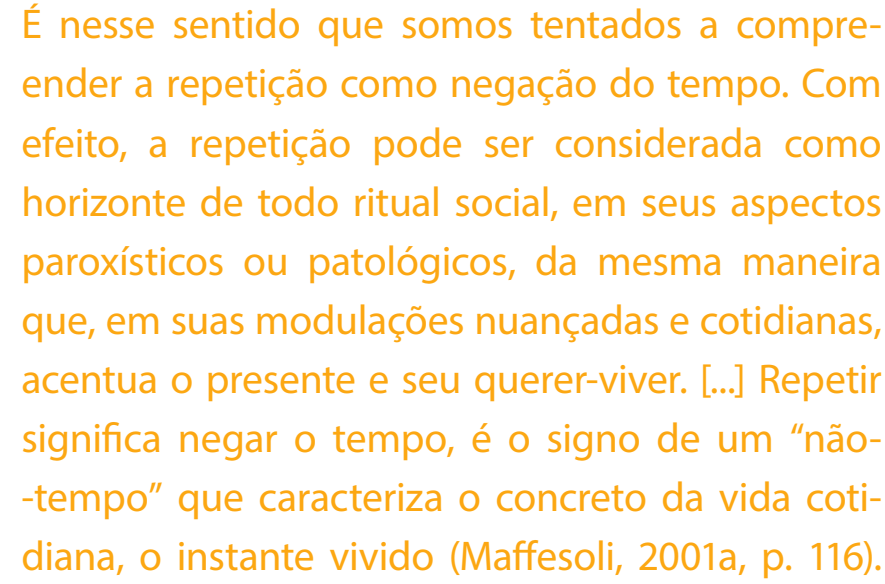

A pós-modernidade evidencia a crise nas ciências, a indefinição de limites sobre a doença mental e a premência do corpo como repositório do mal-estar. A performatividade da doença, expressa no comportamento, dá concretude à patologia para ser exibida nas páginas do jornal e suscitar a emoção do leitor.

\section{Considerações finais}

Observamos que as matérias revelam o imaginário da pós-modernidade. O jornalismo promove o compartilhamento de sentidos, principalmente nas cidades em que o ritmo acelerado de vida e a necessidade de se manter informado fazem com que as pessoas recorram às notícias. As grandes cidades concentram os maiores índices de transtornos mentais, devido ao ambiente caótico que satura a mente, e ao acesso mais facilitado à informação. Daí a importância do jornalismo como ordenador da realidade social, permeando a fragmentação e a intensidade da vida urbana.

Compreendemos que o imaginário se expressa na saturação da identidade observada na midiatização do sofrimento. Há a expressão do mal-estar, a identificação de pessoas com a doença, a exterioridade dos afetos, a empatia e a busca de apoio. $O$ trágico se revela na instabilidade que atinge também a esfera emocional e no sofrimento constitutivo do ser humano. Razão e emoção são manifestações da nossa condição existencial. Qualquer pessoa, portanto, pode ser acometida de um transtorno que irrompe em determinado momento da vida.

O corpo paroxístico demarca a manifestação das doenças mentais na forma corporal como uma espécie de encenação. Os medicamentos regulam e aliviam o sofrimento e provocam a medicalização do cotidiano. O desconforto deve ser combatido para que se promova a sensação de bem-estar.

A sociologia compreensiva descreve e compreende o imaginário, partindo dos pressupostos que rejeitam a separação entre pesquisador e objeto e considera a complexidade e o paradoxo que constituem os fenômenos. Observamos os relatos do cotidiano expressos na Folha de S. Paulo e como o discurso sobre o sofrimento possibilita a conectividade, a exteriorização dos afetos e a criação de socialidades. O dispositivo jornalístico, considerado uma tecnologia do imaginário, tende a agregar as pessoas dispersas nas grandes cidades, onde o ritmo acelerado desencadeia a "saturação dos nervos" e requer novas formas de interação.
Referências

ASSOCIAÇÃO NACIONAL DE JORNAIS (ANJ). Brasília, 2014. Disponível em: <http://www.anj.org.br/maioresjornais-do-brasil/>. Acesso em: 15 jun. 2015.

BIRMAN, Joel. O sujeito na contemporaneidade: espaço, dor e desalento na atualidade. Rio de Janeiro: Civilização Brasileira, 2012.

BOTTON, Alain de. Notícias: manual do usuário. Rio de Janeiro: Intrínseca, 2015

DUNKER, Christian Ingo Lenz. Mal-estar, sofrimento e sintoma: uma psicopatologia do Brasil entre muros. São Paulo: Boitempo, 2015.

INSTITUTO DE PSIQUIATRIA DA UNIVERSIDADE DE SÃO PAULO (IPqUSP); ORGANIZAÇÃO MUNDIAL DE SAÚDE (OMS). São Paulo Megacity Mental Health Survey. 2012. Disponível em <http://www.plosone.org/article/fetchobject. action? uri=info\%3Adoi\%2F10.1371\%2Fjournal. pone.0031879\&representation=PDF $>$. Acesso em: 15 abr. 2014.

LEGROS, Patrick; MONNEYRON, Frédéric; RENARD, JeanBruno; TACUSSEL, Patrick. Sociologia do imaginário. 2. ed. Porto Alegre: Sulina, 2014.

MAFFESOLI, Michel. Dinâmica da violência. São Paulo: Vértice, 1987.

MAFFESOLI, Michel. O imaginário é uma realidade. In: Revista Famecos. Porto Alegre: PUCRS, v. 8. n. 15, p. 74-82, ago. 2001 
MAFFESOLI, Michel. A conquista do presente. Natal: Argos, 2001a.

MAFFESOLI, Michel. 0 instante eterno: o retorno do trágico nas sociedades pós-modernas. São Paulo: Zouk, 2003.

MAFFESOLI, Michel. 0 tempo das tribos: o declínio do individualismo nas sociedades de massa. 4. ed. Rio de Janeiro: Forense Universitária, 2006.

MAFFESOLI, Michel. O conhecimento comum introdução à sociologia compreensiva. Porto Alegre: Sulina, 2010.

MAFFESOLI, Michel. Saturação. São Paulo: lluminuras; Itaú Cultural, 2010a.

MORIN, Edgar. 0 método 5: a humanidade da humanidade. 4. ed. Porto Alegre: Sulina, 2007.

ORGANIZAÇÃO MUNDIAL DA SAÚDE (OMS). Relatório Mundial da Saúde: saúde mental: nova concepção, nova esperança. Lisboa: OMS, abr. 2001.

SILVA, Juremir Machado da. Tecnologias do imaginário. 3. ed. Porto Alegre: Sulina, 2012.

SIMMEL, Georg. As grandes cidades e a vida do espírito (1903). Mana, Rio de Janeiro, v. 11, n. 2, Oct. 2005 Disponível em <http://www.scielo.br/scielo.php?script=sci_ rttext\&pid=S010493132005000200010\&lng=en\&nrm=iso >. Acesso em: 22 jan. 2015.

\section{Matérias citadas}

CÉZARI, Marcos. Pressões e problemas urbanos colaboram para afastamento. Folha de S. Paulo, São Paulo, ano 91, n. 30.186, 25 nov. 2011. Mercado, p. B7.

ESTUDO relaciona esquizofrenia com vírus. Folha de $S$. Paulo, São Paulo, ano 81, n. 26.306, 11 abr. 2001. Folha Ciência, p. A14.

FRAGA, Érica; BORLINA FILHO, Venceslau. Afastamentos por doenças mentais disparam no país. Folha de S. Paulo, São Paulo, ano 91, n. 30.186, 25 nov. 2011. Mercado, p. B6.

MALDJIAN, Mayra. Viciados em manias. Folha de S. Paulo, São Paulo, ano 91, n. 30.112, 12 set. 2011. Folhateen, p. 4-5.

MASSARANI, Luísa. Brasileiros criam diagnóstico para pânico. Folha de S. Paulo. São Paulo, ano 81, n. 26.515, 06 nov. 2001. Folha Ciência, p. A10.

MEDEIROS, Roberta. Doença mental afeta mais criança favelada. Folha de S. Paulo. São Paulo, ano 81, n. 26.275, 11 mar. 2001. Folha Vale, p. C1.

STRINGUETO, Kátia. Motivação evita recaída no alcoolismo. Folha de S. Paulo. São Paulo, ano 81, n. 26.240, 04 fev. 2001. Cotidiano, p. C10.

VALDEJÃO, Renata de Gaspari. Problema mental pode ser 'camuflado'. Folha de S. Paulo. São Paulo, ano 81, n. 26.429, 12 ago. 2001. Cotidiano, p. 10.
VERSOLATO, Mariana. O teste dos temperamentos. Folha de S. Paulo. São Paulo, ano 91, n. 29.972, 25 abr. 2011. Cotidiano, p. C10.

\section{Notas}

1 Doutora em Comunicação Social (PUCRS/Bolsista CAPES). Professora da Universidade Federal do Maranhão - UFMA (Av. Dos Portugueses, 1966, Vila Bacanga, CEP 65085-580, São Luís/MA, Brasil). Email: dayres42@gmail.com.

2 Doutor em Educação (PUCRS). Professor titular da Pontifícia Universidade Católica do Rio Grande do Sul - PPGCOM/PUCRS (Av. Ipiranga, 6681, Partenon, CEP 90619-900, Porto Alegre/RS, Brasil. Email: rr@pucrs.br. 